\title{
Like Cream: Valuing the Invaluable
}

\author{
JULIEN MCHARDY \\ MARTIN LUTHER UNIVERSITY
}

\begin{abstract}
Julien McHardy draws on his work with the alternative publishing collective Mattering Press to explore the importance of opening up and maintaining "bewildering spaces within" the increasingly normative and clear-cut regimes of evaluation. Drawing on a range of examples from alternative publishing, the artwork "The Right to be Lazy" and concepts of care, love, qualculation and laziness, McHardy argues that opening up space for otherness within are crucial to good academic work. At the same time, he also warns us that caring for difference is a struggle that includes making radical cuts and disconnections, and in practice often may build on precarious and invisible work. This leads him to asks what academic institutions would look like that could value and cultivate that which they cannot evaluate.
\end{abstract}

\section{Keywords}

indicators; indicator game; evaluation; publishing; open access

\section{Introduction}

The Hamburger Bahnhof, now a museum of contemporary art, used to be the terminus of the Berlin-Hamburg railway in Berlin. In the middle of the square, in front of main entrance of the neoclassical building, lies a somewhat bewildering bed. Like the central pathways, this bed too is box-edged, but the land thus framed looks unkempt. Left since 2009 when the Californian artist John Knight instructed the museum's gardeners to leave all but the box untouched, this piece of land has grown into a piece of art, named after Paul Lafargue's manifesto, "The Right to be lazy." Situated in the middle of one of Germany's most prominent art venues, the shrub studded round opens the question of how we might make space for practices and collectives that do not fit with the commercial and bureaucratic rationalities that tend to dominate academic evaluation schemes. In this contribution I lean on Knight's bed to ask how we might harbor and encourage otherness within the box-edges that order our academic landscapes. Knight's work, despite the

Julien McHardy, Email: julien.mchardy@ethnologie.uni-halle.de

Copyright (C) 2017 (Julien McHardy). Licensed under the Creative Commons Attribution Non-commercial No Derivatives (by-nc-nd). Available at estsjournal.org. 
garden metaphor, does not appeal to romantic binaries. The bed-untouched is not other to the trim box but wasteland within, kin to that strip by the highway. If the bed is not romantic it isn't hybrid either. Below ground roots might mingle but the point is that borders are maintained, allowing difference to persist. "The Right to be Lazy" yields neither wilderness nor mash-up but the possibility of bewildering alterity within. With regards to our conversation in this ESTS thematic collection, this opens the question if and how academic institutions can cultivate and value that which they cannot evaluate. I will approach this wider question through a series of short reflections on my work with the open access publisher, Mattering Press. I argue that Mattering Press can be understood as an attempt to create a space for difference within established academic publishing practices.

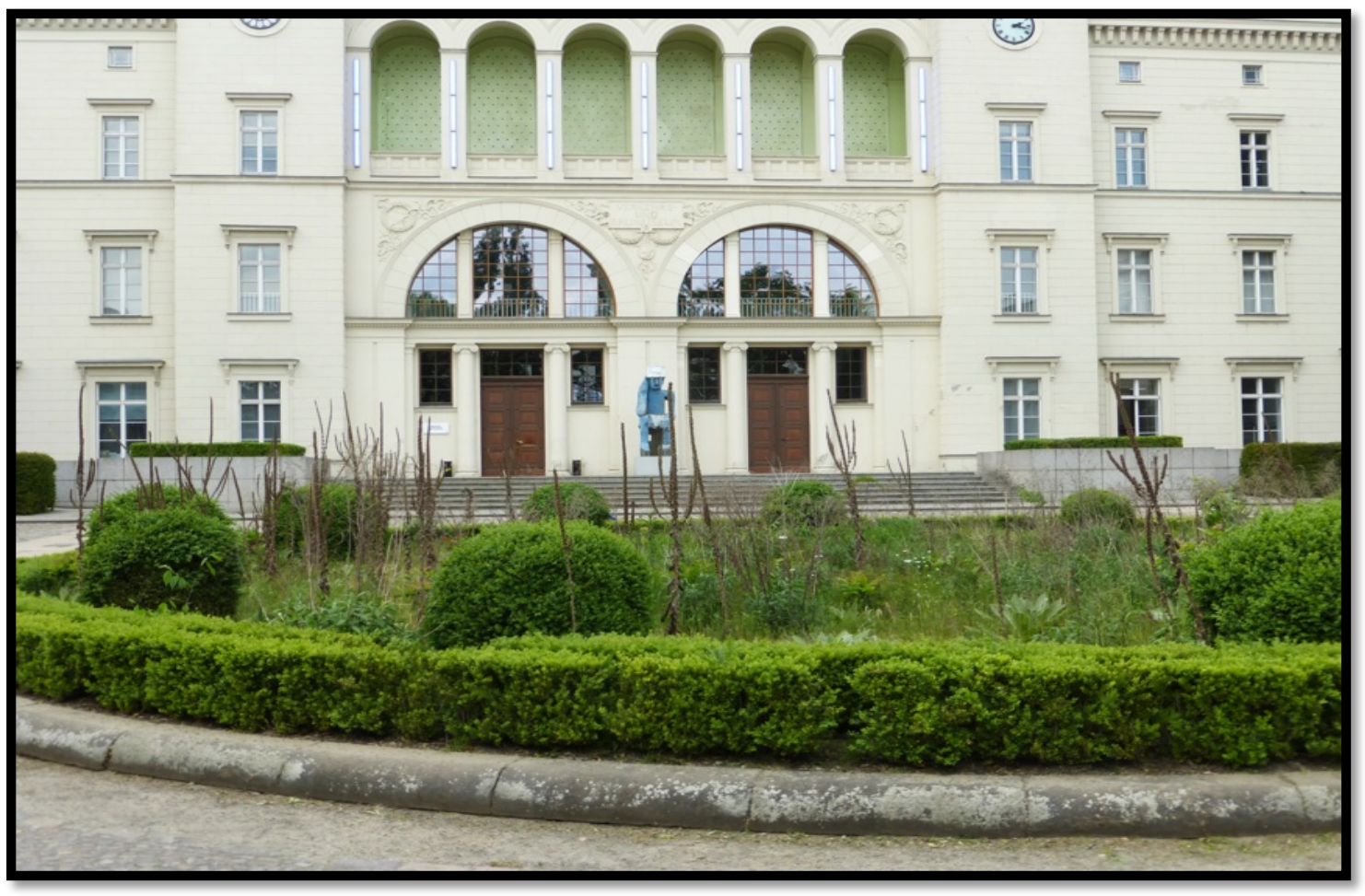

“The Right to be Lazy"-Photo by Tahani Nadim

\section{Collectives}

Dissatisfied with the current publishing landscape, particularly for early-career researchers, Uli Beisel, Endre Dányi and developer Ed Akerboom started Mattering Press in 2012 at a time when academic open access book publishing just started to gather momentum. I joined the press in 2013 and it is now run by a group of six editors that includes Natalie Gill, Michaela Spencer and 
Joe Deville. As STS scholars we learn that critique is a practical endeavour. The making of the Press can be understood as a critique of mainstream academic publishing by means of a practical experiment. Experimenting with desirable forms of academic publishing is a timely concern because what academic books are, what they should cost, who will make them, who will pay for them and how they are accounted for are all questions that are up for grabs as the infrastructures and politics of academic knowledge production are changing. The digitalization of print production and distribution and related debates about appropriate forms of copyright and open access thus open up new possibilities, stakes and politics. One such possibility is to rethink books, authors and publishers as collectives, rather than bounded entities.

In 2016 we published our first four books after a long process of learning and experimentation. We would not have gotten this far without the support of a small group of academic open access publishers such as Open Humanities Press, Goldsmith Press, Punctum Books, Meson Press and Hybrid Publishing Lab, ${ }^{2}$ all of which are busy building a collective of alternative academic presses that can share and further practical and theoretical concerns related to publishing. Precisely because we are not in a competitive relationship with our fellow open access publishers the boundaries between the presses remain relatively malleable. So far this is just a thought experiment, but we are, for example, discussing the possibility of publishing a text on publishing at the same time in different formats in different presses. One of the key insights from a Mattering Event that my colleagues ran at the 2016 4S / EASST conference was that authors are attracted to Mattering Press partly because they seek ways of high quality publishing that do not imply a competitive relationships with their fellow scholars. Offering workshops around particular book projects is one way of building on this insight. Experiments with non-competitive forms of writing and publishing embed us in a collective form that is wider than the entity we are staking out. Within its stricter boundaries, too, the press is a collective achievement. It is supported and constituted by our STS and open access advisory board members, web developer, proof readers, copy editors, typesetter and designer as well as our peer group, the "Flows, Doings, Edges" collective a number of small but generous grants and donations.

All entities can be conceptualized as collectives, but collectivity needs to be rendered evident in order to become productive. This is what we try to do for publishing, writing and reading practices. Organizing workshops around particular book projects is part of this work. We try to show that books are collective efforts by making more evident the work of copy editors, proof readers, designers and typesetters. As a part of this we acknowledge this work that often remains invisible in the preface of our books, after we parked more radical plans to place filmstyle production credits on the cover. We also try to pay fairly those who do not have direct stakes in the academic circuit, such as proof readers and designers-although this is much more difficult considering tight budgets and the assumption of free labor on which much academic publishing rests. Going beyond acknowledgment we try to find ways of practicing books and publishing as collective objects and practices. We are, for example, looking to change review

2Check out www.openhumanitiespress.org, www.gold.ac.uk/goldsmiths-press, https:/ / punctumbooks.com, www.meson.press, www.hybridpublishing.org 
processes from a series of judgements (see also Pontille, Torny 2014) into sustained collaborations between reviewers, authors and editors, where reviewers might agree to comment on several versions of a text from proposal to manuscript. This has been particularly useful when working with early career researchers. Making room for new kinds of collectives is one way of creating openings for difference within.

\section{Openings}

One such collective that we engaged in through conversations with fellow presses, workshops and conferences emerges at the growing intersection of the open access movement and Science and Technology Studies. Within the open access community openness tends to be treated as a universal good, a positioning that is in tension with our STS informed skepticism of universal claims. I draw on my co-editors Endre Dányi and Joe Deville here who have argued elsewhere that creating openings for alternative ways of doing publishing is more productive, for us at least, than a demand for universal openness (2014). Sarah Kember from Goldsmiths Press has elaborated that open access introduces new restrictions on what can and cannot be published (2016). The free availability of texts as digital files that is referred to as open access often implies that books are paid for upstream in the production process, by authors or research projects rather than downstream by libraries and readers. No longer keeping out readers who are unwilling or unable to pay, the paywall now potentially keeps out authors who are unable to front the costs. Given that most departments allocate limited print budgets under the pressure of achieving high impact it should be clear that moving payment upstream can disadvantage or make impossible more experimental or early-career book projects. This potential closure has become more pressing since open access has been taken up by major funding bodies, some of which require that all funded work is published open access. What this means for how open access books are financed or not is still unclear.

Currently there is no best practice, only experimentation. One starting point for experimentation is to question the industrious vocabulary that turns book projects into distinct one-way streams flowing from writer to reader, boxed off by paywalls. Who says that books flow downhill? We too heavily depend on books that come with funding but all funding we attract goes into a common reservoir fed by book sales, donations from readers and supporters and small institutional grants. In this way better funded projects effectively subsidize other books allowing us to publish those that come with little or no direct funding. Being able to support books with limited funding matters particularly because we set out to provide fellow early career scholars in the field of Science and Technology Studies with a platform to develop and publish high quality open access monographs. Being able to support early career scholars, however, depends on a credible press backed by the reputation and funding of established scholars. That is one of the reasons why only one of our first books is from an early-career scholar. As the Press begins to mature and grow, so will our capacity to take on texts from early career researchers. Financing such work remains challenging but we currently have three monographs from Early Career Researchers in the pipeline, and look forward to being able to support more in the future. 


\section{Books}

In significant if not unique ways our books differ from academic conventions. They are available for free as html, pdf, mobi and epub files from our website. This, together with our creative commons licensing, means that technically and legally the cover no longer binds the content of the book. Texts can circulate and be remade in different formats, the consequences of which are yet to be explored. The free availability of the books combined with a pop-up plea for donations before you download means that their price proper is not issued but remains an open issue. We work to open up what our books can be, but in many ways they remain conventional. Conventions such as standardized peer review, stable bounded books that can be cited and counted and individual heroic authors that can be credited for singular works are built into academic publishing, academic careers, and academic lives and thoughts. Staying within these edges is but one and arguably a relatively conservative strategy for allowing other logics and conventions to take center stage in publishing. Open Humanity Press' Liquid books and Living books series, for example, explicitly undo the authored book offering instead a more permeable, malleable and perhaps more lively text. Mainly because we aim to cater to early career researchers who depend on countable books as building blocks for their careers we decided to stay within and therefore reproduce many of the conventions of academic publishing, including those that make auditing possible.

But why should (young) STS scholars write books? This question was asked by a participant of a publishing workshop that I gave in 2014 for the Spanish Science and Technology Studies network esCTS. Why indeed should we write and publish books if machine indexed articles are the currency in which our value and opportunities as (young) STS scholars are measured? I love to break a spine and my attachment to books is not easily accounted for by any single register, but it is neither nostalgic nor essentialist. It is not attachment to the book as we know it but to the book format that offers difference within the conventions of the bounded cover. The tension between the relatively fixed format and the experimentation it affords is central to book magic. This is perhaps especially so in times when the conventions of the book and the infrastructures on which it relies are changing, inviting and requiring extensive experimentation with what a book is, could and should be. How, if and when books register in regimes of evaluation differs between disciplines and countries, of course, and there are plenty of uninspired books as well as mind-blowing articles. In full recognition of the many experimental articles and journals (take Limn or Demonstrations ${ }^{3}$ for example) I maintain that experimenting with the bounded format of books continues to open possibilities for risky, strange, rigorous, inventive, un-disciplinary, unruly and collaborative texts. Experimenting with book formats is one strictly non-romantic, non-nostalgic starting point for practicing book love.

${ }^{3}$ Check out www.limn.it, www.ojs.gold.ac.uk/index.php/demonstrations 


\section{Love}

Love is not a model for business. But holding on to careful and unpredictable forms of attachment is one way of working towards a space that is not primarily governed by bureaucratic or business logics. Whenever we say that our books are available for free download we are asked: "What is your business model?" This question normalizes certain ideas about economical viability and value. It evokes a world where businesses can be modelled and where business thus defined is the model for all, academic enterprises included. If we want to open up space within the narrow hearted normativity that the concept imposes this seemingly commonsensical question ought to be reformulated in a different register. "Every time I hear it I want to say love, love is our business model: Precarious, productive, scary, unpredictable, high stake." (Note from a publishing workshop, Leuphana University, Lüneburg, 2013).

We still do not have a business model and in this we are in good company. The trustfunded Guardian for example, is frequently attacked for not having a viable business model yet the paper is doing rather well by focusing on building relationships with their readers and funders that do not start and end at a paywall (see for example Chittum 2014). A recent study of almost 400 titles publishes across 20 American University Presses tried to calculate the full costs of a digital monograph including press overheads and staff time that often are not properly considered when calculating the cost of books. Producing a digital monograph costs between between $\$ 30,000$ and $\$ 50,000 \$$, the study estimates (Maron, Mulhern, Rossman, Schmelzinger 2016). There are no models, business or otherwise, for how these costs can and should be covered for academic monographs, most of which will sell no more than a few hundred copies. At a moment when established models of publishing are disintegrating, having a business model is probably not going to save you. Opening up room for experimenting with other types of attachments and relationships, however, might.

\section{Box-edges}

Nuff love. Setting up a press is to build an institution and in order to do so box-edges must be defined and maintained. Positioning the press, maintaining its boundaries and experimenting with different practices and infrastructures in ways that create the possibility for invaluable difference within is edge-work that entails moments of audit and calculation. As publishers, we are concerned with numbers, sales, visibility, profit, tweets and reputation. So, auditors are not aliens but versions of ourselves, as Strathern has it $(1997,319)$. This said, Strathern asks what version of ourselves we want as our auditors? As far as the press is concerned this too must be an experiment. We are working hard to make sure that our books are well accounted for and I do feel satisfied if the cross-sums add up, but we work even harder to make sure that bookkeeping logics do not dominate our book making. Box-edges order the press but we try to change moments where order is imposed, such as peer review, from moments of judgment to moments of collaboration, care and support-relations that go beyond the number produced. We are committed to an "open review" process, for example. Within this box-edge we try to accommodate that for a particular collective of authors, reviewers and books a different process 
might be more productive. The same is true for our licensing, the regime that formalizes books as fixed units of intellectual property or as collectives objects. We settled for the Creative Commons Attribution-NonCommercial-ShareAlike (CC-BY-NC-SA) as our box-standard license, because it allows texts to circulate in different formats while retaining acknowledgment of authorship that continues to be crucial for academic recognition. Despite our commitment here too, the boxstandard isn't enforced and we are willing to negotiate a different licence should that be more productive. Boundaries are blurry in practice and good intentions do not necessarily play out right, but it matters that our commitment in these two examples is not to compromise. This is not about ways of working around the box-edges but about box-edges designed to accommodate different kinds of working. It is about commitment to give room to different kinds of collectives and the conditions they require.

Two conceptual tools from the repertoire of STS that we have found useful to approach this edge-work are the concepts of non-qualculation and care. The term non-qualculation was coined by Frank Cochoy to indicate that seemingly abstract calculations always entail moments of qualitative judgment (2008). In relation to our conversation this means for example that qualitative judgments are built into the calculations by which indicators are derived. Making Cochoy's awkward neologism more awkward still, Callon and Law invite us to think about the relationship between qualculation and non-qualculation (Callon and Law 2005). Reflecting on the ways in which Quaker worship defies qualculation, Callon and Law argue that making things countable (qualculation) and keeping things out of accountability regimes (non-qualculation) are both practical achievements. In relation to book making I understand this to mean that good book making is about box-edges that negotiate calculative demands in such a way that other logics than those of calculation may become viable. These are questions that invite experimentation, because if making room for non-qualculability is a practical task, it should be clear that there are many possible ways of aiming for it. The press is registered as a charity in Manchester and does not belong to any particular academic institution. Registering as a charity and all the book keeping this involves is one example of the work that it takes to remain accountable in ways that allow us to stay out of academic regimes of accountability.

The feminist concept of care has become important in STS (through the work of people such as Hilary Rose, Annemarie Mol, Jeannette Pols, Ingunn Moser and Vicky Singleton) to mark vital relations and practices whose value cannot be calculated and thus often goes unacknowledged where logics of calculation are dominant. At Mattering Press, thinking about care helps to make visible the on-going and collaborative work of authors, reviewers, editors, copy editors, proof readers, typesetters, distributers, designers, web developers and readers. But care is not the other of calculation. Rather, care can help to engage with calculative logics, such as those of costs, without granting them dominance. How do we calculate so that calculations do not dominate our considerations? What would it be to care for rather than to calculate the impact of a book? Can we imagine evaluation jargon that is derived from practices of care rather than those of domination and force? What would be an appropriate instrument to gauge the effects and affects of a book for example, if impact is too blunt an instrument? 


\section{Cutting-edges}

A relational approach to care does not exclude the possibility that care sometimes requires cutting edges. In her essay on how we might know and think with care, María Puig de la Bellacasa notes "Where there is relation, there has to be care, but our cares also perform disconnection" (2012). Caring for Knight's bed, to return to the opening trope, certainly requires a pair of sharp shears. As a small publisher one issue where care might involve disconnection rather than workarounds is a question about how we might relate to the two companies that dominate the print on demand industry on which we rely. Print on demand (POD) means that books are no longer printed in editions and stocked for sale. Instead books are printed and shipped on demand, individually when ordered. Integrated services that handle the logistics from webshop to delivery means that publishers do not need to invest in storage or large print editions, thus dramatically reducing overhead. The recent emergence of small independent publishers rests on that of large-scale print on demand infrastructures. Mattering Press' ability to deliver print editions depends entirely on this offering. Together with the majority of small publishers we are therefore fully dependent on just two companies who dominate the POD industry. Create Space is owned by the electronic commerce giant Amazon and Lightning Source is owned by the Ingram Content Group, a large company that dominates book distribution in the USA. There is no space here for details and there is no easy solution, but we are in conversation with other presses about the possibility of a shared online presence and webshop that would allow us to increase the visibility and margins of independent academic publishers. It is a different question if we will ever have the resources and energy to attempt this. My point is that this would create a radical disconnect that would effectively cut out Amazon. Without radical cuts that go beyond workarounds the possibilities of imagining and putting into practice alternative print on-demand infrastructures remain limited. Yet, the possibility for more radical cuts is largely missing from our conversation in this thematic issue.

With this in mind I return to the opening question of how academic institutions can value the kind of invaluable spaces, collectives and objects that they cannot evaluate. It should be clear by now that invaluable as I understand it here is not an essential quality but a relational achievement, an achievement that sometimes might require cutting edges. David Stark, for example, has argued that successful high tech entrepreneurs create spaces where experimentation can take place by keeping them out of regimes of valuation (2009). Maximilian Fochler in a similar vein has shown that good academic group leaders go through great efforts to keep part of their group's work out of calculation and accumulation dynamics (2016). In both examples a space is cut out from the demand for immediate accountability. Our conversation in this issue brings out many ways in which academics work around regimes of evaluation in order to get the work done that they value. Roland Bal, for example, outlines three ways in which he and his colleagues make room for their research practices and values by working around and partially reworking institutional demands (Bal 2017). This is a valuable contribution but our conversation has little to say about how more radical disconnections and cuts might be enacted. I worry that this omission and the consequent focus on playing "the system" severely limits our ability to imagine and fight for scholarly institutions of publishing and evaluation that can value 
and harbor invaluable difference within.

\section{Late Again}

That it is late again as I am writing this serves as a tired reminder that my pledge for bewildering collectives within does not even start to address the question how (young) scholars in precarious employment might find the strength, time and resources to open and maintain them. Mattering Press receives some institutional recognition and funding but our work and that of most contributors remains unpaid. Working for free, the collective subsidizes the press through other paid work, or by staying up late again. A reminder that making spaces of otherness, such as our private lives and nights productive for dominant logics is not what we are after.

How does the figure of the precarious academic laboring into the night sit with the right to be lazy? Badly, and this is the crux. Above I alluded to love in an attempt to open space for difference within the narrow normative register of business model speech. Laziness might do something similar for work opening up questions about what counts as work, as output and as quality. Lafarge's manifesto "The Right to be Lazy," that gave Knight's bed its name calls for "a brazen law forbidding any man to work more than three hours a day" (1883). Lafarge's argument, in short, is that any form of creative expression requires laziness. Laziness here is not the other of work but an attempt to think productivity in a richer register than that of work. Laziness is one entry point to rethinking what counts as good academic practice without getting immediately bound up in the normative quantification of work. In the absence of institutions that value laziness, precarization arguably is the price we pay at Mattering Press to partially escape accountability. Clearly, we have not figured out how to write "New Songs to New Music," as Lafarge puts it in the end of his manifesto. This does not mean that experimentation should be aborted but that maintaining spaces of otherness is not a game (of evaluation or otherwise) but a struggle, still.

\section{Acknowledgments}

I would like to thank Rebeca Ibáñez Martin, Vincenzo Pavone, Pablo Santoro, Santiago López Garcia and Guillem Palà for co-organizing the Publish like you give a Damn workshop where the first version of this text originated. I would like to thank Endre Dányi, Joe Deville, Natalie Gill, Tjitske Holtrop and Michaela Spencer for their comments and the editors Sarah de Rijcke and Maximilian Fochler for their careful editing. And finally, thanks to Tahani Nadim for her photo of "The Right to be Lazy."

\section{Author Biography}

Julien is a sociologist of science and technology and associated researcher at the Martin Luther University, Halle. He works as a freelance researcher, designer, strategist, editor and cultural 
producer. Working across several fields he is bringing his background in design and sociology to projects that combine design, strategic and theoretical work.

\section{References}

Bal, R. 2017. "Playing the Indicator Game: Reflections on Strategies to Position a Group in a Multidisciplinary Environment." Engaging Science, Technology, and Society 3: 41-52. DOI:10.17351/ ests2016.111.

la Bellacasa, de, M. P. 2012. "Nothing comes without its world: thinking with care." The Sociological Review, 60(2): 197-216. http:/ / doi.org/10.1111/j.1467-954X.2012.02070.x

Callon, M. and J. Law. 2005. "On qualculation, agency, and otherness." Environment and Planning D: Society and Space, 23(5): 717-733

Chittum, R. 2014 "The trust-fund newspaper: The Guardian's windfall ensures its long-term future." Columbia Journalism Review, January 30. Accessed 2 June 2016. http:/ / www.cjr.org/the_audit/the_trustfund_newspaper.phphttp://www.cjr.org/the_audit/the_trust-fund_newspaper.php

Cochoy, F. 2008. “Calculation, Qualculation, Calqulation: Shopping Cart Arithmetic, Equipped Cognition and the Clustered Consumer." Marketing Theory 8 (1): 15-44

Dányi, E. and J. Deville. 2014. "From Openness to Openings: Reflections on the Experiments in Knowledge Production workshop" CISP Online, June 18. Accessed 2 June 2016. http:/ / www.csisponline.net/2014/06/18/ from-openness-to-openings-reflections-onthe-experiments-in-knowledge-productionworkshop/http:/ / www.csisponline.net/2014/06/18/ from-openness-to-openingsreflections-on-the-experiments-in-knowledge-production-workshop/

Fochler, M. 2016. "Variants of Epistemic Capitalism: Knowledge Production and the Accumulation of Worth in Commercial Biotechnology and the Academic Life Sciences." Science, Technology \& Human Values. doi: 10.1177/0162243916652224.

Kember, S. 2016. "How open is Open Access?" The Bookseller Accessed September 32016. http://www.thebookseller.com/blogs/how-open-open-access-333306

Lafargue, P. 1883. The Right To Be Lazy and Other Studies. London: Charles Kerr and Co. Online Version: Lafargue Internet Archive. Accessed June 222016. https: / / www.marxists.org/archive/lafargue/1883/lazy/

Maron, N. C. Mulhern, D. Rossman, and K. Schmelzinger, K. 2016. "The Costs of Publishing Monographs: Toward a Transparent Methodology." Ithaka S+R. Accessed 14 October 2016. http:/ / dx.doi.org/10.18665/sr.276785

Stark, D. 2009. The Sense of Dissonance: Accounts of Worth in Economic Life. Princeton, New Jersey: Princeton University Press

Strathern, M. 1997. "Improving ratings': audit in the British University system." European Review 5 (03): 305-321. doi:10.1002/(SICI)1234- 981X(199707)5:3<305::AID-EURO184>3.0.CO;2-4.

Paenhuysen, A. 2012. "The Right To Be Lazy. John Knight and Siegfried Kracauer" An Paenhuysen Blog, Accessed September 3 2016. http: / / anpaenhuysen.blogspot.nl/2012/07/the-right- 
to-be-lazy-john-knight-and.html

Pontille, D. and D. Torny. 2014. "The blind shall see! The question of anonymity in journal peer review" Ada: A Journal of Gender, New Media, and Technology, 4. 